\title{
Role of Private Sector in Dissemination of Agricultural Information among Cotton Growers in Punjab Pakistan
}

\author{
Muhammad Yaseen ${ }^{1, *}$, Badar Naseem Siddiqui', Muhammad Ali ${ }^{2}$, Muhammad Ameen ${ }^{3}$ \\ ${ }^{1}$ Agricultural Information Institute, Chinese Academy of Agricultural Sciences, Beijing China, \\ (Lecturer, Agric. Extension, UCA-UOS, Sargodha, Pakistan) \\ ${ }^{2}$ Department of Agricultural Extension and Communication, PMAS Arid Agriculture University, Rawalpindi, Pakistan \\ ${ }^{3}$ Department of Agricultural Engineering, PMAS Arid Agriculture University Rawalpindi, Pakistan \\ *Corresponding email: yaseen99pk@yahoo.com
}

Copyright (C) 2014 Horizon Research Publishing All rights reserved.

\begin{abstract}
The present study was designed to assess the role of private sector in dissemination of agricultural information among cotton growers of Rajan Pur district of Punjab province, Pakistan. All the cotton growers were considered as the population of the study. The sample of the population was limited to 120 farmers selected through simple random sampling techniques. The data were collected through personal interviews with the help of interview schedule. The data were arranged and organized on a tally sheet interpretation. The results revealed that private sector contribute momentous role in dissemination of agricultural information among cotton growers. Private sector should increase their role to boost up agriculture. Furthermore, agriculture department should rethink about their working strategies to play their role in dissemination of information to farmers, which is their duty.
\end{abstract}

Keywords Private Extension Services, Agricultural Information, Sources of Agri, Information, Plant Protection Technologies

\section{Introduction}

Agriculture being the largest sector of the economy, assumes the pivotal position in economic development of Pakistan. It accounts for $21 \%$ of the GDP and employs about $45 \%$ of the total employed labor force. Majority (63\%) of country's population living in rural areas is directly or indirectly linked with agriculture for its livelihood [5]. Cotton (Gossypium hirsutum L.) an important silver of the world enjoys a unique position among cash crops of Pakistan and is the life blood of foreign exchange earnings. It contributes substantially to the national income. Raw cotton and cotton based products are the main export of the country. It accounts for $8.6 \%$ of the value added in agriculture and about $1.8 \%$ of GDP. In spite of such a vital importance, per hectare yield of cotton in Pakistan is $712 \mathrm{~kg}$ [6]. That yield is much less than that of many countries of the world like Australia (1808 kg), Syria $(1519 \mathrm{~kg})$, Turkey $(1290 \mathrm{~kg})$, Brazil (1192 kg), China (1109 kg), USA (947 kg) and Egypt $(904 \mathrm{~kg})$ [16]. This low yield may be attributed to a number of factors like lack of knowledge about the use of plant protection measures, non-adoption of latest plant protection technologies by the growers, low seed quality, pest damaging varieties, improper picking practice, inadequate stick cutting practices, high cost of pesticides and lack of finance [4]. The Extension wing of Agriculture Department is responsible for educating the farmers about latest agriculture technologies, but due to wide area, limited resources of the country and inadequate number of extension personnel, the objective is not being achieved fully. Realizing the critical role of plant protection measures especially in cotton production, the private sector came forward to under-take this venture. The poor performance of public sector extension compelled Government of Pakistan to involve more stakeholders to share the responsibilities of diffusion of information to farming communities. The decision was made after 1988, when the National Commission on Agriculture recommended to the government that the traditional role of the private corporate sector in providing material agricultural inputs and services needs to be strengthened and expanded to cover newly emerging needs such as specialized cultivation operations, spraying, and harvesting and to provide total package services rather than single inputs [7]. In light of the commission's recommendations, multinationals such as Ciba-Geigy, Bayer, Hoechst and others began taking part in extension work as well as selling agricultural inputs. Both the sectors have some reservations as public service agents often argue that private companies react only on profit motivations and are unconcerned with addressing social goals. On the other side, the private sector often criticizes the bureaucracy and inefficiency of the public sector, which is seen as unable to respond to the demands of industrial development [12].Today, the involvement of the private sector including nongovernmental organizations (NGOs) in 
extending farm technologies to farmers is gaining momentum and proved to be better choices as among many funding agencies [14] which is the reaction of continuous failure of the public sector agricultural extension services to respond to the needs of millions of resource-poor farmers [3] [9] and [15]. Similarly, in a time of growing economic liberalization, the role of profit-making private companies and traders in extending agricultural technologies to farmers is equally important [11]. Some experts predict that private sector extension will play a dominant role in the coming century. However, globally the concept of partnership is growing fast.

These private sectors are basically supposed to popularize and sell their own products, besides providing some useful information to the growers regarding the use of their products. At present, a number of private sector such as Sygenta, FMC, Bayer, Auriga, Taeget, Agrolet, Welcon and other generic companies are performing their role in educating the farming community. [13] It was reported that private extension agencies used a variety of extension teaching methods to popularize their product among the farming community of Baluchistan, a province of Pakistan. A huge amount of money is being invested and spent by the private sector in this business. The present study was therefore, designed to assess the effectiveness of private sector in providing extension services with reference to plant protection practices to the cotton growers. [1] concluded that a great majority (93.3\%) of the respondents had favorable attitude towards the use of pesticide and $80.66 \%$ respondents were satisfied with the information conveyed to them through demonstrations conducted by Granules (Pvt.) Limited. [10] Reported that all the respondents were aware of chemical and cultural plant protection measures of cotton and out of them $90 \%$ were aware of the mechanical techniques in this regard. Farmer field schools (FFS) were organized in Nepal for informal education on integrated pest management (IPM). Several new technologies were demonstrated including safer insecticides, biological control agents and traditional and cultural methods [8]. [2] Respected that the extension methods like farm visits, home visit and general meetings were mostly used and considered as effective means for the dissemination of improved sugarcane cultivation practices by the mills field staff. A huge amount of money is being invested and spent by the private sector in this business. The present study was therefore designed to assess the eff3ectiveness of private sector in providing extension services with reference to plant protection practices.

\section{Methodology}

\subsection{Universe and Population of the Study}

District Rajanpur is situated on the right side of the Indus River. This is agriculture area producing wheat, cotton and sugar cane for the Pakistan. Thirteen (13) million population is living in district Rajan pur. Rajan pur district has three tehsil namely: Jampur, Rajanpur and Rojhan. There are 44 union councils in the district. Agriculture in Rajanpur, depends solely upon canal irrigation. The five rivers of the Punjab (Bias, Chinab Jehlum, Ravi, and Satluj) meet near the Rajan pur and provide water for irrigational and for domestic purpose. The district is famous for growing cotton and sugarcane however, farmers cultivating wheat and rice as well. All the cotton growers of district Rajan Pur of Punjab province were considered as the population of the study.

\subsection{Sample and Procedure for Sample Selection}

The sample of the population was limited to 120 farmers selected through multi-stage-random random sampling technique. During 1978, T\&V system of extension was introduced in Pakistan as well in Punjab. Under this system the front line worker (Agriculture Officer) was deputed at markaz level in Punjab which was consisted on eight union councils. Previously, district Rajan Pur had eight makaz level (eight AOs) but later on two posts were abolished due to some reasons, at present district have six markaz i.e. Fazil Pur, Muhammad Pur, Jam Pur, Kot Mithan Rajan Pur and Rojahan. In order to have representation of entire area, at first stage one markaz from each tehsil was selected randomly and at second stage, two villages from each markez were selected by employing the same method.At final stage, 20 cotton growers were selected by utilizing random sampling technique to make a sample size of 120 respondents for the study.

\subsection{Data Collection Instrument}

The data were collected through personal interviews with the help of carefully developed interview schedule which was pre-tested on 15 non-sampled farmers to make necessary addition/deletion in the instrument. Split-half method was used to check the reliability of the data which was 0.875 .

\subsection{Data Collection and Analysis}

Data was collected through personal interviews of the farmers at their farms or home. The data were arranged and organized on a tally sheet (Excell 2007), data were tabulated and percentages were worked out for their interpretation.

\section{Results and Discussions}

Table 1 indicates that an overwhelming majority (98.3\%) of the respondents got agricultural information through pesticide dealers. Fellow farmers appeared another important source of information as reported by a vast majority $(82.5 \%)$ of the respondents followed by private sector $(45.0 \%)$ and TV (31.7\%). Agriculture department and radio were least important sources of information.

Fig. 1 indicates that majority $(65.8 \%)$ of the respondents was not at all satisfied with the working of private sector. 
However, about 20 and $15 \%$ of the respondents were partially and fully satisfied with the working of private sector respectively.

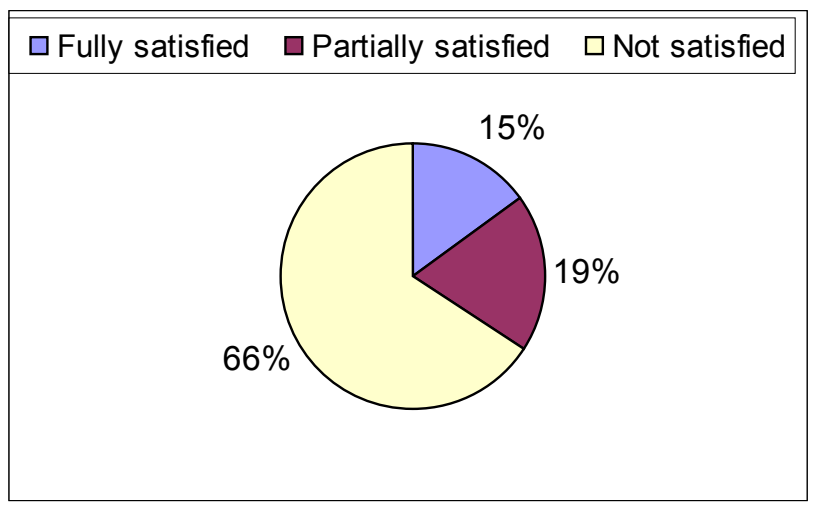

Figure 1. Response Regarding Satisfaction

Table 2 shows that chemical control of pests/diseases and medium categories. However, chemical control tended towards medium and resistant varieties tends toward low categories and was ranked 1 st and 2 nd with weighted score of 142 and 113 respectively. Chemical weed control, seed treatment and manual weed control came in between very low and low categories while chemical weed control tended towards very low categories and were ranked 3rd, 4th, and 5 th with weighted score of 80,54 , and 36 respectively.

\section{Conclusion}

An over helming majority (98.3\%) of the respondents got information through pesticide dealers. Fellow farmers appeared another important source of information as reported by a vast majority $(82.5 \%)$ of the respondents followed by private sector (45.0\%) and TV (31.7\%). Agriculture Department and radio were least sources of information, which were $5.8 \%$ and $9.2 \%$ of the respondents respectively.

Table 1. Distribution of respondents according to their sources of information

\begin{tabular}{|c|c|c|c|}
\hline & Information Source & Number & Percentage \\
\hline \multicolumn{4}{|c|}{ A. Government sector } \\
\hline & a. Agriculture Department & 07 & 5.83 \\
\hline & b. Radio & 11 & 9.16 \\
\hline & c. $\mathrm{TV}$ & 38 & 31.7 \\
\hline \multicolumn{4}{|c|}{ B. Privete sector } \\
\hline & a. Seed dealers & 54 & 45.00 \\
\hline & b. Pesticide Dealers & 118 & 98.33 \\
\hline & c. Fertlizer dealers & 97 & 80.83 \\
\hline \multicolumn{4}{|c|}{ C. Other sources } \\
\hline a. & Fellow Farmers & 99 & 82.33 \\
\hline b. & Progressive Farmers & 26 & 21.33 \\
\hline c. & Printed Material & 14 & $11.7 \%$ \\
\hline
\end{tabular}

Table 2. Ranking of plant protection measures advised by private sector for cotton crop

\begin{tabular}{|c|c|c|c|c|}
\hline Plant Protection Measures & Weighted Score & Ranked Order & Mean & SD \\
\hline Chemical control of pest diseases & 142 & 1 & 2.68 & .92 \\
\hline Use of resistant varieties & 113 & 2 & 2.17 & 1.00 \\
\hline Chemical weed control & 80 & 3 & 1.90 & .66 \\
\hline Seed technology & 54 & 4 & 1.10 & .47 \\
\hline Manual weed control & 36 & 5 & 1.24 & .65 \\
\hline
\end{tabular}




\section{Recommendation}

The role of private sector in agriculture sector is encouraging, but private sector should concentrate upon convincing the farmers about importance of technical knowledge and skills about plant protection. The staff of private sector should follow regularity/punctuality in their visit to the farmers. They must pay more visits to farmers and hold meetings with them so that farmers could get maximum information from private sector.

\section{REFERENCES}

[1] Abbasi, I. J. Study of the effectiveness of result demonstrations conducted by Granulars (Pvt.) limited to introduce their insecticide/pesticide among cotton growers of Khanewal district. M.Sc. (Hons.) Agri. Ext. Thesis, Univ. of Agri., Faisalabad, 1986.

[2] Asghar, M. Perceptions of sugarcane growers regarding the working efficiency of extension personal of Kamalia Sugar Mills in Toba Tek Singh district. M.Sc. (Hons.) Agri. Ext. Thesis, Univ. of Agri., Faisalabad, 2000.

[3] Ashby, J. A., T. Gracia, M. P.Gurrero, C. A. Quiros, J. I. Roa, and J. A. Beltran. Institutionalizing farmer participation in adaptive technology testing with the CIAL'. AgRen Paper No. 57, 1995.

[4] Farkade, B.C., R.D. Ahire, N.R. Patange and P.S.Ahire. Constraints in adoption of biological pest control in cotton. MAU, Parbhani, India. J. Soil and Crops. 9(2: 185-187), 1999.

[5] Government of Pakistan, Economic Survey of Pakistan, Finance Division, Economic Advisor's Wing, Islamabad, 2012.

[6] Government of Pakistan, Economic Survey of Pakistan, Finance Division, Economic Advisor's Wing, Islamabad,
2007.

[7] Government of Pakistan. Report of National Commission of Agriculture. Islamabad, Pakistan, 1988.

[8] Gyawali, B. K. and V. M. Salokhe. Farmer Field Schools: a participatory outreach research approach on safe application of agro-chemicals and bio-products. Proceedings of the International Workshop on Safe and Efficient Application of Agro-chemicals and Bio-products in South and Southeast Asia, Bangkok, Thailand: 177-184, 1997.

[9] Howell, J. Accountability on Extension Work In: G.E. Jones (ed.). Investing in Rural Extension: Strategies and Goal. London: Elsevier Applied Science Publishers, 1986.

[10] Hussain, A. A study of the extent of adoption of insect/pest and diseases control measures in cotton crop in tehsil Dera Ghazi Khan. M.Sc. (Hons.) Thesis, Dept. of Aghri. Ext., Univ. of Agri., Faisalabad, 1988.

[11] IFAD. Technology generation and diffusion. Extracted from Internet'. Page maintained by Roxanne Samii, 1995.

[12] ISNAR. New Agriculturist Online www.isnar.cgiar.org/ppp/publications.htm (http://www.new-agri.co.uk/03-4/countryp.html, 2003.

[13] Mengal, A. A., M. U. Mallah, Z. A. Mirani and B. N. Siddiqui. An analysis of public and private agricultural extension Services in Baluchistan, Pakistan. Pakistan J. Agric. Res., 25(4): 10-21, 2012.

[14] Ojha, G. P. Partnership between government, nongovernment and private organization in agricultural extension in east Chitwan, Nepal. Ph.D. Thesis, University of the Phillipines, Los Banos (Unpublished), 1999.

[15] Rivera, W. M. Agriculture extension in transition worldwide: Structural, financial and managerial strategies for improving agricultural extension. Pub. Admin. Develop., 6(868): 1-11, 1996.

[16] USDA. World Agriculture Production. US. Dept. of Agriculture, Foreign Agriculture Services, Washington, DC, 2004. 